\title{
Knowledge of Preconception Care and Associated Factors among Pregnant Mothers with Pre-existing Diabetes Mellitus in selected Governmental Hospitals, Addis Ababa Ethiopia
}

\section{Aychew Kassie}

Mizan-Tepi University, School of Nursing, Mizan-Tepi University

Tigistu Gebreyohannis Gebretensaye ( $\nabla$ tgebreyohannis@yahoo.com )

University of Nottingham School of Health Sciences https://orcid.org/0000-0002-2292-7865

Mesfin Abebe

Addis Ababa University College of Health Sciences School of Nursing and Midwifery

\section{Research article}

Keywords: preconception care, pregnant mothers, diabetes mellitus

Posted Date: August 4th, 2019

DOl: https://doi.org/10.21203/rs.2.12398/v1

License: (c) (i) This work is licensed under a Creative Commons Attribution 4.0 International License.

Read Full License 


\section{Abstract}

Background: Many women with diabetes mellitus experience high rates of unintended pregnancies, infant morbidity and mortality and preventable birth defects. Thus, preconception care offers the potential for earlier risk assessment and intervention that can benefit women before pregnancy and ensure the healthiest possible start for the newborn child. The aim of this study is to assess the knowledge and experience of preconception care and associated factors among pregnant mothers with pre-existing diabetes mellitus. Methods: Facility based quantitative cross-sectional study design was employed among 142 conveniently selected pregnant women between March 11 and April 12, 2018. Logistic regression including bivariate and multivariate analysis considering $95 \% \mathrm{Cl}$ was utilized to examine association between dependent and independent variables. P-value $<0.05$ was considered statistically significant. Result: this study found that $67(42.7 \%)$ of pregnant women with pre-existing diabetes mellitus had good knowledge on preconception care. Educational level, occupation and duration of diabetes was associated with knowledge about preconception care AOR $=0.24[0.065,0.828], A O R=0.042[0.102(0.011$ $0.918]$ and $A O R=0.035$ [3.599(.095-11.833] respectively. Conclusion: women's knowledge on preconception care in this study is low. Education, occupation and duration of diabetes were factors associated with knowledge of preconception care. Establishment of preconception care strategies addressing all components of the care and increasing women's knowledge about preconception care is an important component to ensure prevention of potential risks.

\section{Introduction}

\section{Background}

Diabetes mellitus (DM) is a global epidemic and common medical conditions in pregnancy. The incidence of the disease during pregnancy is rapidly increasing mainly in type two diabetes mellitus cases. The rise is associated with an increase in the prevalence of overweight and obesity in the population (1). An estimated 28 million women of reproductive age are suffering from diabetes mellitus worldwide. Majority of these women have type 2 diabetes and $80 \%$ of the burden is found in low and middle income countries (2). Normal pregnancy itself is regarded as a diabetogenic state in which postprandial glucose levels are elevated and insulin sensitivity is decreased due to the effects of placental hormones, growth factors, and cytokines(3). This complex hormonal adaptations that work to ensure adequate glucose availability and the relatively reduced insulin sensitivity contribute to hyperglycemia which makes pre-existing diabetes even worse during pregnancy. Diabetes mellitus increases risk of pregnancy related complications like: preeclampsia, infections, obstructed labor, postpartum hemorrhage, preterm births, stillbirths, macrosomia, carriage, intrauterine growth retardation, congenital anomalies, birth injuries and death in the pregnant mother and her unborn child (4)Pregestational diabetes occurs before pregnancy and this includes type one and type two diabetes mellitus, whereas, gestational diabetes mellitus (GDM) exists during pregnancy. Studies also reported that, the risk of development of type 2 diabetes in later life is 7- to 9.6-times higher among gestational diabetic cases 
(5). Pregnant mothers with Pre-existing diabetes, (both type one and type two) are at greater risk of pregnancy complications and likewise pregnancy can make diabetes worse. Pregnancy in individuals with known diabetes requires planning and adherence to strict treatment regimens. Intensive management and normalization of the blood glucose level are essential for individuals with pre-existing diabetes who are planning pregnancy. Preconception care is a care needed to prepare a woman for pregnancy at least six months earlier to conception (6). The care is provided to all diabetic mothers planning pregnancy for the first time or between consecutive pregnancies(7). According to some studies, pregnancy outcomes can be significantly improved by intensifying therapies, rigorous glycaemic control and avoidance of teratogenic medicines(8). A diabetic woman planning to conceive also needs to be aware about the implementation of preconception care components including medication review, folic acid supplementation, weight reduction, smoking cessation counseling, improved nutrition and exercise, as well as addressing other diabetes-related health problems (9). The care is particularly important as fetal development commences in the first trimester of pregnancy. As reported by some studies, diabetic women receiving preconception care more likely to have favorable pregnancy outcomes, including lower rates of congenital anomalies and spontaneous abortions(10). Therefore, this study was conducted to assess the knowledge level of preconception care and associated factors among pregnant mothers with pre-existing diabetes mellitus in selected governmental hospitals.

\section{Methods}

Facility based quantitative cross-sectional study design was employed in six governmental hospitals with diabetic follow-up services in Addis Ababa the capital city of Ethiopia were included. The hospitals were Black lion, Zeweditu memorial hospital, Yekatit 12, Ras Desta Damtew, Minlik II and St. Paul's hospitals. One hundred forty two pregnant mothers with pre-existing diabetes mellitus were conveniently included between March 11 and April 12, 2018. Selection of the hospitals was based on presence of follow-up services for diabetic patients and all hospitals having follow-up service were included. All pregnant mothers with pre-existing diabetes on diabetic follow up earlier than the current pregnancy were included. A structured adapted and modified data collection instrument prepared by reviewing different literatures was used to gather the information. The instrument was translated to the local language for ease of administration and later back translated to English. This instrument involved four parts which include: Socio-demographic, Obstetric history, maternal diabetic condition and knowledge about preconception care. Six data collectors were recruited and trained to gather the information and the principal investigator supervised the whole process of data collection. Ethical clearance and permission letter was obtained from responsible organizations and consent was obtained from respondents. Knowledge was measured based on respondent's correct response to preconception care knowledge questions. Those respondents who correctly respond to $50 \%$ or more of the preconception care knowledge questions were considered to have good knowledge and those who scored $<50 \%$ were considered as having poor knowledge $(11,12)$. The data was coded and entered into Epi-data version 4.2 .0 then exported to statistical package for social science (SPSS) version 25. Descriptive statistics and logistic regression 
including bivarriate and multivariate analysis was used and a statistical significance was considered at p-value $<0.05$, and $95 \%$ confidence interval.

\section{Results}

\section{Socio demographic characteristics and obstetric history of study participants}

A total of 145 participants were enrolled in this study, and 142 participants responded to the questions that makes the response rate $97.9 \%$. Most participants were above 30 years old with mean age 36.65 and $\mathrm{SD} \pm 4.31$. All respondents were married, 54 (38\%) of respondents and $67(47.1 \%)$ of their husbands completed college and above and $62(41.3 \%)$ of the respondents were government employee (Table 1$)$.

Regarding their obstetric history, 93 (65.5\%) of respondents had less than two pregnancies including current pregnancy, 99 (69.7\%) of them had history of contraceptive use, about one fourth $45(31.7 \%)$, had history of unplanned pregnancy, $36(25.3 \%)$ abortion and $26(18.3 \%)$ had history of stillbirth (Fig. 1).

Maternal diabetic condition: More than half 79(55.6\%) were type two diabetes with duration of diabetes mean 6.96, SD \pm 2.12 and (range 3-15 years). Among those who were type two, 26(33.0\%) of them were diagnosed as gestational diabetes. Sixty-five (45.7\%) of them had less than one month diabetic follow up before current pregnancy, thirty-six (25.3\%) have diabetic related complication or co-morbidity (Table 2).

\section{Knowledge on preconception care}

Among the total 142 participants, 103(72.5\%) know the services provided during pre-pregnancy /preconception visit. From those who know the services provided; blood sugar control, contraceptive counseling, folic acid supplement and advice on diet and weight control were reported as a preconception care component by $70.4 \%, 67.9 \%, 50 \%$ and $32.4 \%$ of respondents respectively.

\section{Knowledge about preconception care}

Preconception care knowledge level was measured based on correct response to eight preconception care knowledge questions. The minimum and maximum score of participants ranged between zero and seven. Of the total, $67(47.2 \%)$ respondents scored greater than $50 \%$ and were considered to have good knowledge and the remaining $75(52.8 \%)$ respondents score was less than $50 \%$ and regarded as having poor knowledge. (Fig. 2)

\section{Response of pregnant women with preexisting diabetes to Knowledge questions}


Among the total respondents, 103 (72.5\%) were aware about preconception care service being provided in the hospitals. Participants were asked about to whom preconception care is needed, and $54(38.1 \%)$ said to all pregnant women with diabetes mellitus, while 47 (33\%) said only for diabetic pregnant women with chronic illness. Of all the participants, 97 (68.3) knew about the purposes of preconception care. Participants were also requested about the length of good blood sugar control before conception and 85 (59.9\%) respondents reported the do not know, while 17 (12\%) said three months, 33 (23.2\%) two months and few 7 (4.9) reported one month. Of the total, 38 (26.8\%) knew that pregnancy worsens condition of diabetes, 78 (54.9\%) knew about the need of folic acid supplement during pregnancy, of which, 51 (65.3\%) said folic acid supplement should be started before pregnancy and 19 (24.3\%), said.after pregnancy [table 3]

\section{Factors associated with knowledge of preconception care}

In this study, education, occupation and duration of illness were found to be factors associated with knowledge of preconception care among women with preexisting diabetes mellitus. Those mothers with educational level of primary school were less likely to have good knowledge as compared to those women with educational level of college and above AOR $=0.233$ [0.065-0.828]. Occupation was another factor associated with knowledge about preconception care among women with pre-existing diabetes mellitus. Government employee women with diabetes mellitus were less likely to have good knowledge compared to others, AOR $=0.102$ [0.011-0.918], and duration of diabetes was also associated with knowledge about preconception care. Those pregnant women with duration of diabetes less than five years were more likely to have good knowledge as compared to those women with duration of diabetes illness greater than five years. [Table 4]

\section{Discussion}

This study have attempted to assess the level of knowledge of preconception care and associated factors among pregnant women with pre-existing diabetes attending diabetic follow up in selected governmental hospitals of the study area.

A total of 142 mothers were studied, of those 103 (72.5\%) respondents reported that they know the preconception care service is provided in the selected hospitals. The study found that $47.2 \%$ of the study participants have good knowledge on preconception care. This finding is consistent with other study findings conducted in Zambia, Saudi Arabia and USA among women with pre-gestational diabetes which reported that the proportion of participants having good knowledge about preconception care is low(1315). Another study conducted in Brazil also found that $51.5 \%$ study participants demonstrated good knowledge on preconception care (16). The narrow discrepancy might be due to differences in socio demographic and/or socio economic characteristics between the two countries.

In this study, education, occupation and duration were found to be the factors associated with women's knowledge about preconception care. Women who attended primary school were less likely to have good 
knowledge on preconception care than those who attended college and above $A O R=0.233[0.065,0.828]$. This finding is supported by a study finding in Zambia where participants who attended primary level of education were 4.54 times more likely to have poor knowledge on preconception care than those with tertiary education(18). Another study in France also showed that those who attended above secondary school were 4.6 times more likely to have good knowledge on preconception care(19). In this study occupation was also found to be associated with women's knowledge about preconception care among pre-existing diabetic patients., Those government employee women were less likely to have good knowledge than those students and market trade vendors $A O R=0.102[0.011,0.918]$. The finding is inconsistent with the study in Zambia, where the employees showed no significant association with knowledge on preconception care P-value (0.131)(20). This may be due to the fact that government employees had limited access to attending educational sessions in the current study. The other factor which showed association with knowledge about preconception care among diabetic women was duration of illness/diabetes. Women with duration of diabetes less than five years were more than three times more likely to have good knowledge on preconception care than those with greater than five years duration $A O R=3.599[0.095,11.833]$. This finding is inconsistent with a study result in France, where participants with duration of diabetes greater than five year were two times more likely to have good knowledge than those less than five years (21).

\section{Limitation of the study}

The study used non-probability sampling technique as the accessible population is limited. The crosssectional nature of the design limits to show cause and effect relationship and it is also prone to recall bias as women's were asked about pre-pregnancy care for the current pregnancy and since the sample size was small, all this may limit generalizability of finding beyond the study settings.

\section{Conclusion}

The level of knowledge about preconception care among pregnant mothers with pre-existing diabetes mellitus in this study is low. Education, occupation and duration of diabetes were factors associated with knowledge of preconception care. Establishing preconception care strategies that can address all components of the care and increasing women's knowledge regarding preconception care may help to reduce risk of maternal and fetal complications. Further large scale studies may be recommended.

\section{Implications for practice}

It has been shown that knowledge of preconception care among women with preexisting diabetes mellitus in this study was low. A diabetic women planning to conceive needs to be aware about the implementation of preconception care(9). Pregnancy in women with known diabetes mellitus requires planning and adherence to strict treatment regimens. The care is needed to prepare a woman planning pregnancy at least six months earlier to her conception, to reduce risk of pregnancy related complications 
like: preeclampsia, infections, obstructed labor, postpartum hemorrhage, preterm births, stillbirths, macrosomia, carriage, intrauterine growth retardation, congenital anomalies, birth injuries and death in the pregnant mother and her unborn child(6). Therefore, the findings of this study will provide direction for health care providers and policy makers to design and implement strategy to address the problem.

\section{Declarations}

Ethics: Ethical clearance was obtained from Addis Ababa University, College of Health Sciences, institutional review committee, permission from Addis Ababa regional health Bureau and from the selected hospital administrative offices. An informed verbal consent was obtained from study subjects confidentiality of information was assured.

Consent for publication: All authors who took part in the study have agreed publication of the article in women's health issue journal.

Availability of Data: The datasets generated and/or analysed during the current study are available in the name http://etd.aau.edu.et/handle/123456789/13486? in the Addis Ababa University repository.

\section{Conflict of interest: None}

Computing of interest: This article has not been published previously and is not under consideration for publication elsewhere.

Funding: This research did not receive any specific grant from funding agencies in the public, commercial, or not-for-profit sectors

Authors' contribution: All authors listed in the title page have equal contribution in the study.

Acknowledgement: We wish to thank the participating hospital for granting permission to collect data and the Research and Ethics Committee, School of Nursing and Midwifery College of Health Sciences, Addis Ababa University and study participants volunteered to participate in the study.

\section{References}

1.Coulthard T HG. Type 2 diabetes in pregnancy; more to come? Practical Diabetes International 2008;25::359-61.

2.IDF. maternal and child health. Brussels, Belgium: International Diabetes Federation(eight edition). 2017.

3.Vargas R, Repke JT, Ural SH. Type 1 diabetes mellitus and pregnancy. Reviews in obstetrics \& gynecology. 2010;3(3):92-100. Epub 2011/03/03. 
4.Negrato CA, Mattar R, Gomes MB. Adverse pregnancy outcomes in women with diabetes. Diabetology \& metabolic syndrome. 2012;4(1):41. Epub 2012/09/12.

5.Bellamy L, Casas JP, Hingorani AD, Williams D. Type 2 diabetes mellitus after gestational diabetes: a systematic review and meta-analysis. Lancet. 2009;373(9677):1773-9. Epub 2009/05/26.

6.McCance DR. Pregnancy and diabetes. Best practice \& research Clinical endocrinology \& metabolism. 2011;25(6):945-58. Epub 2011/11/26.

7.Willumsen J ME. Meeting to develop a global consensus on preconception care to reduce maternal and childhood mortality and morbidity:. Geneva World Health Organization Lancet 2010. 2012;;375 (9730).

8.F. Gary Cunningham KJL, Steven L. Bloom, et al:. Williams obstetrics. text book McGraw-Hill Companies,Inc: United States of America: 23rd ed:. 2010.

9.(NICE) NIfHaCE. Diabetes in pregnancy: management of diabetes and its complications from preconception to the postnatal period. 2015.

10.Anwar A SA, Masson E, Allen B, Wilkinson L, Lindow SW. The effect of pre-pregnancy counseling for women with pre-gestational diabetes on maternal healthstatus. Eur J ObstetGynecolReprod Biol. 2011;155:137-9.

11.Madanat AY, Sheshah EA. Preconception care in Saudi women with diabetes mellitus. Journal of family \& community medicine. 2016;23(2):109-14. Epub 2016/05/18.

12.Patricia Mutale MK. Knowledge and Preconception Care Seeking Practices amongReproductive-age Diabetic Women in Zambia. International Journal of Translational Medical Research and Public Health 2017;1(2):36-43.

13.L CHD. Exploring Knowledge and Attitudes Related to Pregnancy \&Preconception Health in Women with Chronic Medical Conditions. Maternal and Child Health J 2010;14((5)):713-9. doi:10.1007/s10995009-0518-6.

14.M. F. The knowledge of women with diabetes mellitus regarding preconception care and maternal-fetal risks. Revista da Escola de Enfermagem da U S P. 2012;46(1):22-8.

15.Lepercq J. [Pregnancy in type 1 diabetes: insulin pump versus intensified conventional therapy. Gynecol Obstet Fertil 2005;33:389-394]. Gynecologie, obstetrique \& fertilite. 2005;33(11):955-6. Epub 2005/10/26. Grossesse et diabete de type 1: pompe a insuline versus traitement intensifie conventionnel. Gynecol Obstet Fertil 2005;33:389-394.

16.Ferreira M. The knowledge of women with diabetes mellitus regarding preconception care and maternal-fetal risks. Rev Esc Enferm USP 2012; 46(1):22-8.. 
17.Tieu J MP, Crowther CA. Preconception care for diabetic women for improving maternal and infant health. Cochrane Database of Systematic Reviews. 2010.

18.Owens LA AG, Kirwan B, Carmody L, Dunne F.. ATLANTIC DIP: closing the loop. Diabetes Care. 2012; $35: 1669-71$.

19.Mutale P, Kwangu M, Mirriam Kapambwe Muchemwa C, Silitongo M, Chileshe M, Siziya S. Knowledge and Preconception Care Seeking Practices among Reproductive-age Diabetic Women in Zambia Knowledge and Preconception Care among Pregnant Diabetic Women 372017. 36-43 p.

20.Rockville P. Knowledge about preconception care in French women with type1 diabetes: Diabetes Metab., 2010;31(5):443-447

\section{Tables}

Table 1: Socio-demographic characteristics of Pregnant mothers with pre-existing diabetes mellitus in Addis Ababa selected hospitals March 11-April 12, $2018(n=142)$

\begin{tabular}{llll} 
Variable & Category & $\begin{array}{l}\text { Frequency } \\
(\mathrm{N})\end{array}$ & $\begin{array}{l}\text { Percent } \\
(\%)\end{array}$ \\
\hline Maternalage & $<30$ & 41 & 71.1 \\
\hline Maternaleducational status & $\geq 30$ & 101 & 29.9 \\
\hline & No formal education & 14 & 9.9 \\
\hline & Primary school completed & 29 & 20.4 \\
\hline $\begin{array}{l}\text { Educational status of husband(if } \\
\text { married) }\end{array}$ & Secondary school & 45 & 31.7 \\
\hline & College and above & 54 & 38.0 \\
\hline & No formal education & 8 & 5.6 \\
\hline & Primary school completed & 17 & 12.0 \\
\hline Maternaloccupation & Secondary school & 50 & 35.2 \\
\hline & Completed & 67 & 47.2 \\
\hline & House wife & 48 & 33.8 \\
\hline & Government employee & 62 & 43.7 \\
\hline & Private employee & 20 & 14.0 \\
\hline & Others & 12 & $8.5 \%$ \\
\hline
\end{tabular}


Table 2: Maternal diabetic condition among pregnant women with preexisting diabetes mellitus in selected governmental hospitals in Addis Ababa, March 11-April 12, 2018 ( $n=142)$

\begin{tabular}{|c|c|c|c|}
\hline Variables & Category & Frequency & Percent \\
\hline \multirow[t]{2}{*}{ Type of diabetes mellitus } & Type one & 63 & 44.4 \\
\hline & Type two & 79 & 55.6 \\
\hline \multirow[t]{2}{*}{ Ever diagnosed as GDM before (if type two) } & Yes & 26 & 33.0 \\
\hline & No & 53 & 67.0 \\
\hline \multirow[t]{2}{*}{ Duration of diabetes (in years) $(n=126)$} & $<5$ year & 24 & 16.9 \\
\hline & $\geq 5$ year & 102 & 83.1 \\
\hline \multirow[t]{3}{*}{ Frequency follow up before current pregnancy } & $<1$ month & 65 & 45.7 \\
\hline & $1-2$ month & 41 & 28.9 \\
\hline & $\geq 3$ month & 36 & 25.4 \\
\hline Monitor blood sugar at home & & 69 & 48.6 \\
\hline Diabetic related co-morbidity & & 42 & 29.6 \\
\hline \multirow[t]{4}{*}{ Type of diabetic related co-morbidity reported $(n=42)$. } & Hypertension & 28 & 66.7 \\
\hline & $\begin{array}{l}\text { Kidney } \\
\text { problem }\end{array}$ & 7 & 16.7 \\
\hline & $\begin{array}{l}\text { Vision } \\
\text { problem }\end{array}$ & 5 & 11.9 \\
\hline & $\begin{array}{l}\text { Heart } \\
\text { problem }\end{array}$ & 2 & 4.8 \\
\hline \multirow{3}{*}{$\begin{array}{l}\text { Knows availability of Health education sessions regarding } \\
\text { diabetes in pregnancy }\end{array}$} & Yes & 22 & 15.5 \\
\hline & No & 68 & 47.9 \\
\hline & Don't know & 52 & 36.6 \\
\hline \multirow[t]{2}{*}{ Ever attained Educational sessions } & Yes & 13 & 59.0 \\
\hline & No & 9 & 41.0 \\
\hline \multirow[t]{2}{*}{ Consults health care provider between visit } & Yes & 26 & 18.3 \\
\hline & No & 116 & 81.7 \\
\hline
\end{tabular}

$\mathrm{GDM}=$ gestational diabetes mellitus 
Table 3: Knowledge of preconception care among pregnant mother with pre gestational diabetes in selected governmental hospitals Addis Ababa, March 11 to April 12, $2018(n=142)$

Variables

Frequency $(\mathrm{N})$

Percent

(\%)

Know serviceis provided before pregnancy visit

103

72.5

Perception on need of preconception care

For all women planning pregnancy

54

38.1

Only for women with chronic illness

47

33.0

Don't know

41

28.9

Knows benefits of Preconception care

97

68.3

benefit of preconception care (multiple response)

Improve maternal health

73

75.2

Improve pregnancy outcome

70

72.1

Prevent un wanted pregnancy

67

61.8

High blood sugar levels with pregnancy increases risk of birth defect in newborn baby

8

5.6

Length of good blood sugar control recommended before conception

Three month

Two month

33

23.2

One month

7

4.9

Don't know

85

59.9

Pregnancy worsens condition of diabetes mellitus

38

26.8

Seasonal medical check-up for complication like retinal screening is important in addition to s monitoring blood sugar before pregnancy.

Knows about need for folic acid supplementation

Whento start folic acid supplementation $(n=78)$

Before pregnancy

After pregnancy

Don't know

8

6.4

Folic-acid supplement reduce the risk of birth defect in newborn baby $(\mathrm{n}=78)$ 
Table 4: Factors associated with knowledge of preconception care among pregnant mothers with pre gestational diabetes, in Addis Ababa, March 11-April 12, 2018(n=142)

\begin{tabular}{|c|c|c|c|c|c|}
\hline \multirow[t]{2}{*}{ Variables } & \multirow[t]{2}{*}{ Category } & \multicolumn{2}{|l|}{$\begin{array}{l}\text { Knowledge on } \\
\text { PCC }\end{array}$} & \multirow[t]{2}{*}{$\mathrm{AOR}=95 \% \mathrm{Cl}$} & \multirow[t]{2}{*}{$\begin{array}{l}\mathrm{P} \text { - } \\
\text { value }\end{array}$} \\
\hline & & Good & Poor & & \\
\hline \multirow[t]{4}{*}{$\begin{array}{l}\text { Maternal Educational } \\
\text { status }\end{array}$} & $\begin{array}{l}\text { No formal } \\
\text { education }\end{array}$ & $11(16.4 \%)$ & $3(4.0 \%)$ & $\begin{array}{l}0.251(0.040- \\
1.578\end{array}$ & 0.141 \\
\hline & Primary school & $19(28.4 \%)$ & 10(13.3\%) & $\begin{array}{l}0.233(0.065- \\
0.828\end{array}$ & $0.024 *$ \\
\hline & $\begin{array}{l}\text { Secondary } \\
\text { school }\end{array}$ & $13(19.4 \%)$ & $32(42.7 \%)$ & $\begin{array}{l}1.318(0.455- \\
3.819\end{array}$ & 0.611 \\
\hline & $\begin{array}{l}\text { College and } \\
\text { above }\end{array}$ & $24(35.8 \%)$ & $30(40.0 \%)$ & 1 & \\
\hline \multirow[t]{4}{*}{ Maternal Occupation } & House wife & $20(29.9 \%$ & $28(37.3 \%)$ & $\begin{array}{l}0.269(0.031- \\
2.328\end{array}$ & 0.233 \\
\hline & Gov't employee & $39(58.2 \%)$ & $23(30.7 \%)$ & $\begin{array}{l}0.102(0.011- \\
0.918\end{array}$ & $0.042^{*}$ \\
\hline & $\begin{array}{l}\text { Private } \\
\text { employee }\end{array}$ & $6(8.9 \%)$ & $14(18.7 \%)$ & $\begin{array}{l}0.476(0.045- \\
5.038\end{array}$ & 0.538 \\
\hline & Others & $2(3.0 \%)$ & 10(13.3\%) & 1 & \\
\hline \multirow[t]{2}{*}{ Duration of diabetes } & $<5$ years & $6(8.9 \%)$ & $18(24.0 \%)$ & $\begin{array}{l}3.599(.095- \\
11.833\end{array}$ & $0.035^{\star}$ \\
\hline & $\geq 5$ years & $61(91.2 \%)$ & $57(76.0 \%)$ & 1 & \\
\hline
\end{tabular}

\section{Figures}




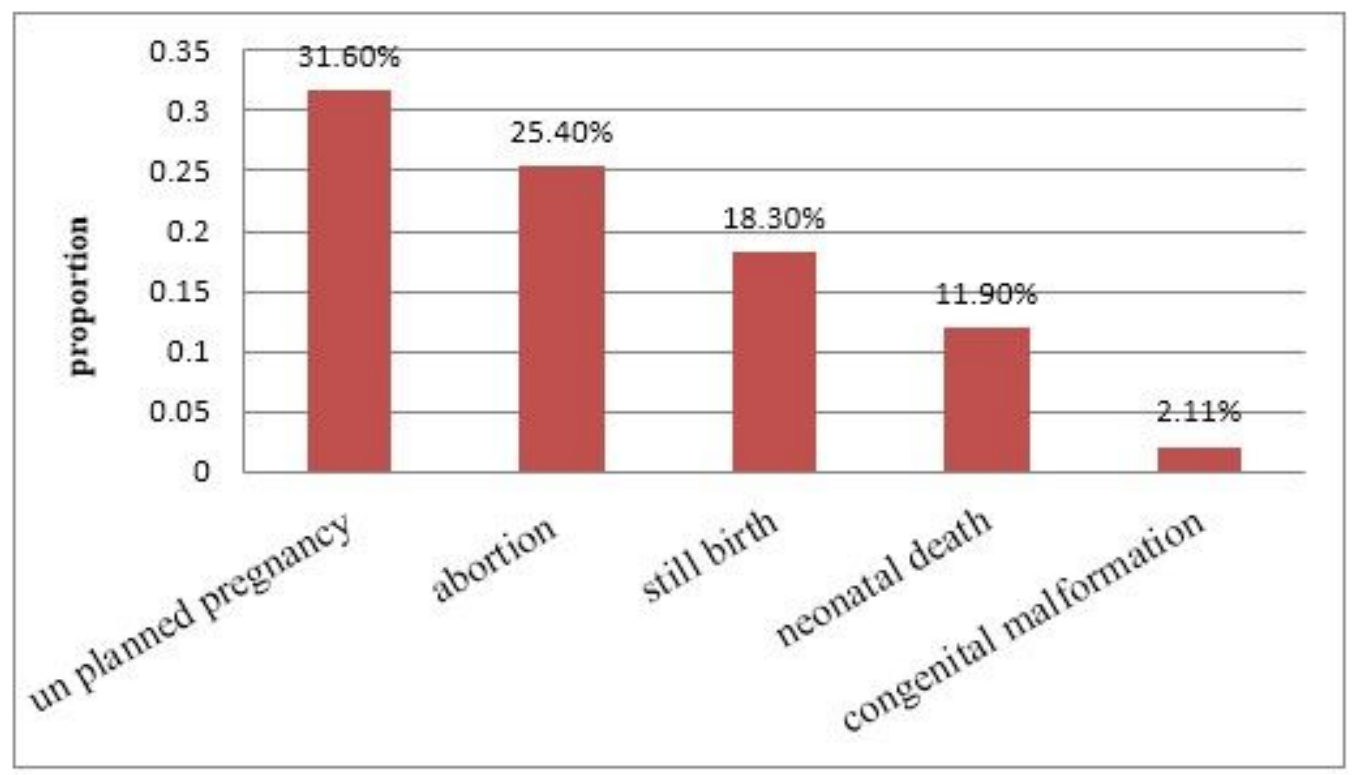

\section{Figure 1}

Obstetric history of pregnant women with pre-gestational diabetes mellitus in selected governmental hospitals, in Addis Ababa March 11-April 12, $2018(n=142)$
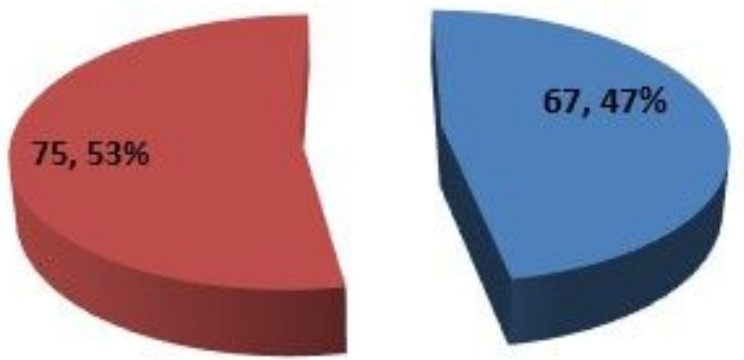

\section{- Good knowledge \\ - Poor knowledge}

\section{Figure 2}

knowledge level of preconception care among pregnant women with pre existing diabetes mellitus in selected governmental hospitals, Addis Ababa, March 11-April 12, $2018(n=142)$ 